Vol. 1 No. 1 Januari 2022, e-ISSN : 2827-8070 | p-ISSN : 2827-8240

\title{
HUBUNGAN SOSIAL EKONOMI IBU DENGAN KELENGKAPAN IMUNISASI PADA ANAK DI WILAYAH KERJA PUSKESMAS GLUMPANG BARO KECAMATAN GLUMPANG BARO KABUPATEN PIDIE
}

\author{
HALIMAHTUSSAKDIAH \\ Akademi Kebidanan Darul Husada Sigli \\ Email : Halimahtusakdiah404@gmail.com
}

\begin{abstract}
ABSTRAK
Pemberian imunisasi berguna untuk memberi perlindungan menyeluru terhadap penyakitpenyakit yang bernbahaya. Dengan imunisasi dasar lengkap sesuai jadwal pemberiannya, tubuh bayi dirangsang untuk memiliki kekebalan tubuh sehingga tubuh mampu melawan serangan penyaki berbahaya. Tujuan penelitian ini adalah untuk mengetahui hubungan Sosial Ekonomi Ibu Dengan Kelengkapan Imunisasi pada anak di wilayah kerja Puskesmas Glumpang Baro Kecamatan Glumpang Baro Kabupaten Pidie tahun 2018. Jenis dan rencana penelitian yang digunakan dalam penelitian ini adalah penelitian Explanatori Reseach dengan pendekatan cross sectional. Explanatori Reseach adalah survei atau penelitian untuk menjelaskan hubungan kausal antara variabelm - variable melalui penguji hipotesa. Populasi dalam penelitian ini yaitu seluruh ibu-ibu yang mempunyai anak yang membawa anaknya untuk di imunisasi pada Puskesmas Glumpang Baro berjumlah 231 orang. Berdasarkan hasil perhitungan jumlah sampel dalam penelitian ini berjumlah 146 orang ibu yang mempunyai anaak di wilayah kerja puskesmas Glumpang Baro Kabupaten Pidie Tahun 2018 adapun tehnik pengambilan sampel dalam penelitian ini menggunakan sampel random sampling yaitu pengambilan sampel secara acak sederhana. Berdasarkan hasil penelitian diperoleh hasil bahwa ada hubungan antara pendidikan dengan kelengkapan imunisasi di Wilayah Kerja Puskesmas Glumpang Baro Kabupaten Pidie ( $\mathrm{p}$ value 0,003) dan ada hubungan antara pendapatan ibu dengan kelengkapan imunisasi di Wilayah Kerja Puskesmas Glumpang Baro Kabupaten Pidie (p value 0,011). Disarankan bagi Puskesmas Glumpang Baro agar dapat meningkatkan kualitas pelayanan kepada masyarakat, terutama dalam hal penyuluhan kesehatan tentang pentingnya pemberian imunisasi.
\end{abstract}

Kata Kunci: sosial ekonomi, pendidikan dan kelengkapan imunisasi

\section{PENDAHULUAN}

Imunisasi adalah pemberian kekebalan tubuh terhadap penyakit dengan memasukkan sesuatu kedalam tubuh agar tubuh tahan terhadap penyakit yang sedang mewabah bagi seseorang (Satiatava, R.P. 2012). Imunisasi merupakan upaya efektif untuk menurunkan angka kematian yang merupakan salah satu tujuan dari Millennium Development Goals (MDGS). Kegiatan imunisasi merupakan salah satu kegiatan prioritas kementrian kesehatan sebagai salah satu bentuk nyata komitmen pemerintah untuk mencapai Millennium Development Goals (MDGS) khususnya untuk menurunkan kematian pada anak. Sustainable Development Goals (SDGS) adalah sebuah dokumen yang akan menjadi sebuah acuan dalam kerangka pembangunan dan perundingan Negara - Negara dunia. Konsep SDGS melanjutkan konsep pembangunan MGDS dimana konsep itu sudah berakhir pada tahun 2015. Jadi kerangka pembangunan yang berkaitan dengan perubahan situasi dunia yang semula mengunakan konsep MGDS sekarang diganti dengan SDGS. Pada dasarnya MGDS dan SDGS punya persamaan dan tujuan yang sama, yakni SDGs melanjutkan cita - cita mulia MDGs yang ingin konsen menanggulangi kelaparan dan kemiskinan didunia. Dokumen yang disepakati oleh pemimpin dunia pada tahun 2000 tersebut habis pada tahun 2015. Para pemimpin dunia merasa agenda MDGs perlu di lanjutka, sehingga muncul sebuah dokumen usulan benama SDGs (Kemenkes RI, 2015). 
Menurut World Health Organization Indonesia memiliki tujuan untuk menurunkan angka kejadian penyakit dan angkia kematian akibat penyakit yang dapat dicegah dengan imunisasi. Upaya imunisasi diselenggarakan di Indonesia sejak tahun 1956. Mulai tahun 1977, upaya imunisasi diperluas menjadi program pengembangan imunisasi dalam rangka pencegahan penularan terhadap penyakit yang dapat dicegah dengan imunisasi campak, tetanus, polio, serta hepatitis B. Imunisasi dasar lengkap pada bayi meliputi BCG, DPT, polio, hepatitis B, campak dan rubela.

Berdasarkan data yang dilansir oleh Kementerian Kesehatan RI, cakupa Imunisasi Dasar Lengkap (IDL) masih mencapai angka 86,8\% pada April 2015. Sedangkan pada tahun 2019, Kemenkes menargetkan cakupa imunisasi perlu ditingkatkan hingga mencapai target 93\%. Fakta di lapangan menunjukkan bahwa masih ada kelompok masyarakat yang belum terjangkau oleh pelayanan kesehatan.

Berdasarkan data terbaru dari Seksi Surveilans dan Imunisasi P2P Dinas Kesehatan Provinsi Aceh, angka cakupan imunisasi dasar lengkap di Aceh belum mencapai target. Pada 2015 angka cakupan Imunisasi Dasar Lengkap (IDL) Aceh yaitu 74\%, sementara pada 2016 malah menunjukkan penurunan menjadi 70\%. Pada 2015 masih terdapat 6 kabupaten/kota dengan angka IDL >90\%, masing-masing Kota Banda Aceh, Aceh Tengah, Aceh Tenggara, Gayo Lues, Bener Meriah, dan Kota Langsa. Sedangkan pada 2016 hanya tiga kabupaten/kota dengan angka IDL >90\%, yaitu Bener Meriah, Kota Langsa, dan Aceh Tenggara.

Berbagai faktor yang menyebabkan makin turunnya angka cakupan imunisasi tersebut dan menjadi tantangan bagi program imunisasi di Aceh adalah karena adanya penolakan dari masyarakat. Baik disebabkan karena ketakutan akan efek demam yang timbul pasca imunisasi ataupun efek lain yang dikhawatirkan terjadi. Para orang tua yang tidak membawa anaknya imunisasi karena sedang sakit di saat jadwal imunisasinya tiba, kemudian terlupa sehingga akhirnya tanpa imunisasi sama sekali.

Berdasarkan data yang diperoleh dari Puskesmas Glumpang Baro Kecamatan Glumpang Baro Kabupaten Pidie Tahun 2018 bayi yang mendapatkan imunisasi HB-0 (13\%), BCG( 33\%), POLIO 1( $32 \%)$, POLIO 2 (34\%), POLIO 3 (29\%), POLIO 4 (25\%), DPT-HB 1 $8 \%$, DPT-HB 2 (23\%), DPT-HB 3 (23\%) dan CAMPAK( 29\%).

Berdasarkan latar belakang di atas, maka rumusan masalah dalam penelitian ini adalah " Hubungan Sosial Ekonomi Ibu Dengan Kelengkapan Imunisasi pada anak di wilayah kerja Puskesmas Glumpang Baro Kecamatan Glumpang Baro Kabupaten Pidie tahun 2018”

\section{METODE PENELITIAN}

Jenis dan rencana penelitian yang digunakan dalam penelitian ini adalah penelitian Explanatori Reseach dengan pendekatan cross sectional. Explanatori Reseach adalah survei atau penelitian untuk menjelaskan hubungan kausal antara variabelm - variable melalui penguji hipotesa (Notoatmodjo, 2012 ). Dalam penelitian cross sectional yaitu jenis penelitian yang menekankan pada waktu pengukuran atau observasi dan variable indepeden dan dependen hannya satu kali pada satu waktu ( Nursalam, 2009 ). Dimana untuk mengetahui atau untuk memperoleh penjelasan tentang Sosial Ekonomi Ibu Dengan Kelengkapan Imunisasi pada anak. jumlah sampel dalam penelitian ini berjumlah 146 orang ibu. Data yang peneliti kumpulkan terdiri dari data primer (peninjauan langsung ke lapangan, baik data ketika diambil pada pengambilan data awal maupun data penelitian) dan data sekunder (data penunjang berupa teori-teori). Peneliti mendatangi semua rumah responden untuk meminta kesediaan responden terlibat dalam penelitian dengan cara membagikan kuesioner, jika responden ketika berlangsungnya penelitian kesulitan untuk diarahkan, maka peneliti akan memberlakukan teknik wawancara terpimpin. Data yang diperoleh kemudian dilakukan pengolahan editing, coding, transferring dan tabulating. Analisa data dilakukan secara deskriptif yaitu dengan melihat persentase dari setiap tabel distribusi frekuensi dan untuk melihat pengetahuan ibu tentang pemberian imunisasi pada bayi. disajikan dalam bentuk tabel distribusi frekuensi untuk ditentukan persentase perolehan tiap-tiap katagori variabel dalam peneltian tersebut. 


\section{HASIL DAN PEMBAHASAN}

Hasil

Penelitian ini telah dilakukan di Wilayah Kerja Puskesmas Glumpang Baro Kecamatan Glumpang Baro Kabupaten Pidie pada tanggal 2 sampai dengan 6 Oktober 2018 dengan cara mendatangi desa saat kegiatan posyandu desa dan memberikan kuesioner kepada sampel sebanyak 146 orang ibu yang memiliki balita. Dari hasil penelitian tersebut maka didapatkan hasil sebagai berikut :

1. Analisa Univariat

Tabel 1. Distribusi frekuensi pemberian imunisasi pada anak

Diwilayah kerja puskesmas glumpang baro kecamatan glumpang baro kabupaten pidie

\begin{tabular}{|c|c|c|c|}
\hline No & Kelengkapan Imunisasi & Frekuensi $(\mathrm{F})$ & Persentase (\%) \\
\hline 1 & Lengkap & 55 & 37.7 \\
\hline 2 & Tidak Lengkap & 91 & 62.3 \\
\hline & & 146 & 100 \\
\hline
\end{tabular}

Sumber : Data Primer ( diolah2018)

Tabel 1 dapat di lihat bahwa mayoritas responden tidak lengkap memberikan imunisasi kepada anaknya lebih banyak yaitu 91 responden $(62,3 \%)$.

Tabel 2. Distribusi frekuensi jenjang pendidikan responden

Di wilayah kerja puskesmas glumpang baro kecamatan glumpang baro kabupaten pidie

\begin{tabular}{|c|c|c|c|}
\hline $\mathrm{No}$ & Pendidikan & Frekuensi $(\mathrm{F})$ & Persentase $(\%)$ \\
\hline 1 & Tinggi & 72 & 49.3 \\
\hline 2 & Menengah & 69 & 47.3 \\
\hline 3 & Dasar & 5 & 3.4 \\
\hline & & 146 & 100 \\
\hline
\end{tabular}

Sumber : Data Primer (diolah 2018)

Tabel 2. dapat dilihat bahwa mayoritas responden berpendidikan tinggi yaitu sebanyak 72 responden $(49,3 \%)$.

Tabel 3. Distribusi frekuensi pendapatan responden di wilayah kerja puskesmas glumpang baro kecamatan glumpang baro kabupaten pidie

\begin{tabular}{|c|c|c|c|}
\hline No & Pendapatan & Frekuensi $(\mathrm{F})$ & Persentase $(\%)$ \\
\hline 1 & Lebih & 57 & 39.0 \\
\hline 2 & Cukup & 34 & 23.3 \\
\hline 3 & Kurang & 55 & 37.7 \\
\hline & & 146 & 100 \\
\hline
\end{tabular}

Sumber: Data Primer ( diolah 2018)

Tabel 5.3 dapat dilihat bahwa mayoritas responden memiliki pendapatan yang lebih yaitu sebanyak 57 responden $(39,0 \%)$.

2. Analisa Bivariat

a. Pendidikan Ibu dengan Kelengkapan Imunisasi

Tabel 4. Hubungan pendidikan dengan kelengkapan imunisasi di wilayah kerja puskesmas glumpang baro kecamatan glumpang baro kabupaten pidie

\begin{tabular}{|c|c|c|c|c|c|c|c|c|c|}
\hline \multirow[t]{3}{*}{ No } & \multirow[t]{3}{*}{ Pendidikan } & \multicolumn{4}{|c|}{ Kelengkapan Imunisasi } & \multirow[t]{3}{*}{ f } & \multirow[t]{3}{*}{$\%$} & \multirow{3}{*}{$\begin{array}{c}\mathbf{P} \\
\text { Value }\end{array}$} & \multirow[t]{3}{*}{$\alpha$} \\
\hline & & \multicolumn{2}{|c|}{ lengkap } & \multicolumn{2}{|c|}{ Tidak Lengkap } & & & & \\
\hline & & $f$ & $\%$ & $\mathrm{f}$ & $\%$ & & & & \\
\hline 1 & Tinggi & 37 & 51.4 & 35 & 48.6 & 72 & 100.0 & 0.003 & 0.05 \\
\hline 2 & Menengah & 17 & 24.6 & 52 & 75.4 & 69 & 100.0 & & \\
\hline \multirow[t]{2}{*}{3} & Dasar & 1 & 20.0 & 4 & 80.0 & 5 & 100.0 & & \\
\hline & Jumlah & 55 & & 91 & & 146 & & & \\
\hline
\end{tabular}

Sumber : Data Primer ( diolah 2018) 
Berdasarkan Tabel 4. dapat di lihat bahwa mayoritas responden yang berpendidikan tinggi memiliki kelengkapan imunisasi yang lengkap yaitu sebanyak 37 responden $(51,4 \%)$, mayoritas responden yang berpendidikan menengah mayoritas memiliki kelengkapan imunisasi tidak lengkap yaitu sebanyak 52 responden $(75,4 \%)$, dan mayoritas responden yang berpendidikan dasar mayoritas tidak lengkap memberikan imunisasi kepada anak, yaitu sebanyak 4 responden $(80,0 \%)$. Hasil uji statistik diperoleh nilai p value sebesar 0,003 yang bermakna ada hubungan antara pendidikan dengan kelengkapan imunisasi di Wilayah Kerja Puskesmas GlumpangBaroKabupaten Pidie.

b. Pendapatan Ibu dengan Kelengkapan Imunisasi

Tabel 5. Hubungan pendapatan ibu dengan kelengkapan imunisasi di wilayah kerja puskesmas glumpang baro kecamatan glumpang baro kabupaten pidie

\begin{tabular}{|c|c|c|c|c|c|c|c|c|c|}
\hline \multirow[t]{3}{*}{ No } & \multirow{3}{*}{$\begin{array}{c}\text { Pendapatan } \\
\text { Ibu }\end{array}$} & \multicolumn{4}{|c|}{ Kelengkapan Imunisasi } & \multirow[t]{3}{*}{ f } & \multirow[t]{3}{*}{$\%$} & \multirow{3}{*}{$\begin{array}{c}\mathbf{P} \\
\text { Value }\end{array}$} & \multirow[t]{3}{*}{$\alpha$} \\
\hline & & \multicolumn{2}{|c|}{ lengkap } & \multicolumn{2}{|c|}{$\begin{array}{c}\text { Tidak } \\
\text { Lengkap }\end{array}$} & & & & \\
\hline & & $\mathrm{f}$ & $\%$ & $f$ & $\%$ & & & & \\
\hline 1 & Lebih & 30 & 52.6 & 27 & 47.4 & 57 & 100.0 & 0.011 & 0.05 \\
\hline 2 & Cukup & 9 & 26.5 & 25 & 73.5 & 34 & 100.0 & & \\
\hline \multirow[t]{2}{*}{3} & Kurang & 16 & 29.1 & 39 & 70.9 & 55 & 100.0 & & \\
\hline & Jumlah & 55 & & 91 & & 146 & & & \\
\hline
\end{tabular}

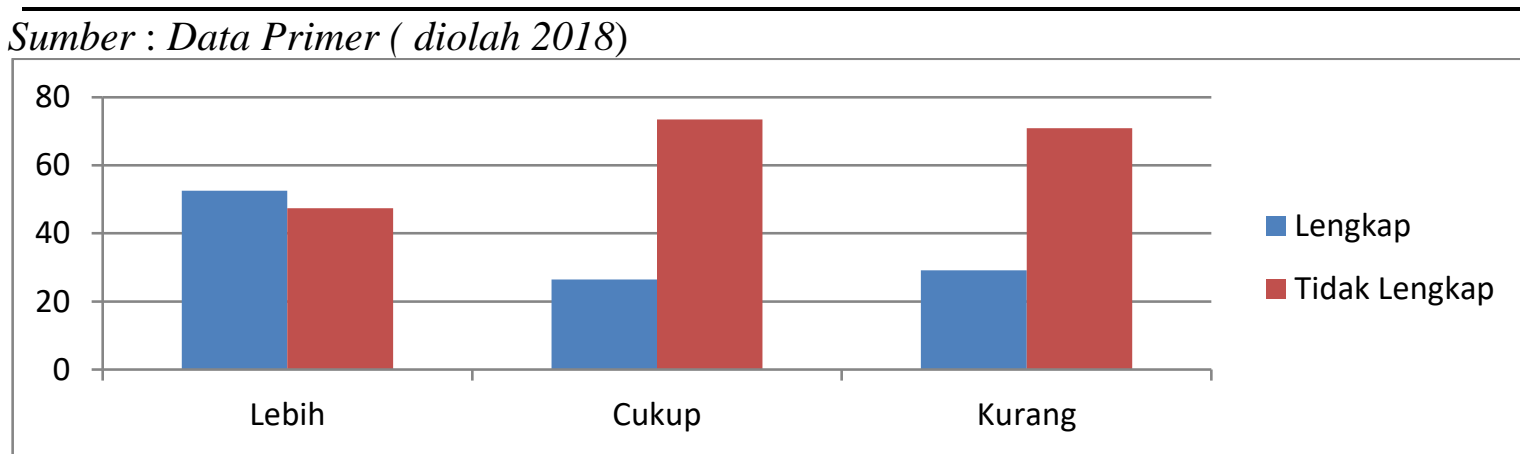

Berdasarkan Tabel 5. dapat di lihat bahwa mayoritas responden yang berpendapatan lebih mayoritas lengkap memberikan imunisasi yaitu sebanyak 30 responden $(52,6 \%)$, mayoritas responden yang berpendapatan cukup mayoritas tidak lengkap memberikan imunisasi yaitu sebanyak 25 responden $(73,5 \%)$, dan mayoritas responden yang berpendapatan kurang mayoritas tidak lengkap memberikan imunisasi yaitu sebanyak 39 responden $(70,9 \%)$. Hasil uji statistik diperoleh nilai $\mathrm{p}$ value sebesar 0,011 yang bermakna ada hubungan antara pendapatan ibu dengan kelengkapan imunisasi di Wilayah Kerja Puskesmas Glumpang Baro Kabupaten Pidie.

\section{Pembahasan}

Penelitian ini dilakukan berdasarkan hasil kuesioner yang diberikan kepada sampel yaitu ibu yang memiliki balita, yang disebut dengan data primer. Sedangkan data sekunder didapatkan dari Puskesmas Glumpang Baro Kecamatan Glumpang Baro Kabupaten Pidie. Pada saat pembagian kueioner kepada sampel, peneliti memberikan arahan dalam menjawab pertanyaan serta tujuan dari penelitian tersebut.

Setelah data hasil terkumpulkan peneliti selanjutnya melakukan rekapan data ke dalam master tabel dan diolah dengan aplikasi SPSS.

Maka dari itu hasil dari penelitian ini disajikan dalam bentuk frekuensi dan distribusi serta penjelasan dalam bentuk narasi sebagai berikut :

\section{a. Hubungan Pendidikan Dengan Kelengkapan Imunisasi Di Wilayah Kerja Puskesmas Glumpang Baro Kecamatan Glumpang Baro Kabupaten Pidie}

Berdasarkan hasil penelitian dapat di lihat bahwa mayoritas responden yang berpendidikan tinggi memiliki kelengkapan imunisasi yang lengkap yaitu sebanyak 37 responden $(51,4 \%)$, mayoritas responden yang berpendidikan menengah mayoritas memiliki 
kelengkapan imunisasi tidak lengkap yaitu sebanyak 52 responden $(75,4 \%)$, dan mayoritas responden yang berpendidikan dasar mayoritas tidak lengkap memberikan imunisasi kepada anak, yaitu sebanyak 4 responden $(80,0 \%)$.. Hasil uji statistik diperoleh nilai p value sebesar 0,003 yang bermakna ada hubungan antara pendidikan dengan kelengkapan imunisasi di Wilayah Kerja Puskesmas Glumpang Baro Kabupaten Pidie.

Konsep dasar pendidikan adalah suatu proses belajar yang berarti didalam pendidikan itu terjadi proses pertumbuhan, perkembangan atau perubahan ke arah yang lebih dewasa, lebih baik dan lebih matang dari individu, kelompok dan masyarakat. Konsep ini berangkat dari suatu asumsi bahwa manusia sebagai makhluk sosial dalam kehidupannya untuk mencapai nilai-nilai hidup dalam masyarakat selalu memerlukan bantuan orang lain yang mempunyai kelebihan (lebih dewasa, lebih pandai, lebih mampu, lebih tahu) (Notoatmodjo, 2005).

Hasil penelitian ini menemukan ada hubungan pendidikan dengan perilaku, dalam hal ini perilaku ibu untuk melengkapi status imunisasi, sesuai dengan teori yang dikemukakan oleh Notoadmodjo (2009), pendidikan merupakan salah satu faktor yang mempengaruhi pengetahuan adalah suatu proses yang unsurnya terdiri dari masukan (input) yaitu sasaran pendidikan (out put) yaitu suatu bentuk perilaku dan kemampuan dari saran-saran pendidikan. Tujuan pendidikan untuk mengubah prilaku masyarakat yang tidak sehat menjadi sehat. Tujuan tersebut dapat dicapai dengan anggapan bahwa manusia selalu dapat belajar atau berubah, karena manusia selama hidupnya selalu berubah untuk menyesuaikan diri terhadap perubahan lingkungan. Apabila tingkat pendidikan seseorang tinggi maka bisa memperbaiki pengetahuan, sikap dan prilakuorang tersebut sehingga mempunyai kesadaran yang tinggi terhadap kesehatan, baik kesehatan pribadi maupun kesehatan keluarga.

Peneliti berpendapat bahwa pendidikan berhubungan dengan kelengkapan imunisasi pada anak, hal ini disebabkan oleh engans emakin tinggi pendidikan, maka akan semakin mengerti dan mengetahui tentang manfaatdan bahaya yang diperoleh dengan pemberian imunisasi pada anak, sehingga ibu menjadi lebih termotivasi untuk memberikan imunisasi yang lengkap kepada bayinya.

\section{b. Hubungan Pendapatan Ibu Dengan Kelengkapan Imunisasi Di Wilayah Kerja Puskesmas Glumpang Baro Kecamatan Glumpang Baro Kabupaten Pidie}

Berdasarkan hasil penelitian dapat di lihat bahwa mayoritas responden yang berpendapatan lebih mayoritas lengkap memberikan imunisasi yaitu sebanyak 30 responden $(52,6 \%)$, mayoritas responden yang berpendapatan cukup mayoritas tidak lengkap memberikan imunisasi yaitu sebanyak 25 responden (73,5 \%), dan mayoritas responden yang berpendapatan kurang mayoritas tidak lengkap memberikan imunisasi yaitu sebanyak 39 responden $(70,9 \%)$. Hasil uji statistik diperoleh nilai $\mathrm{p}$ value sebesar 0,011 yang bermakna ada hubungan antara pendapatan ibu dengan kelengkapan imunisasi di Wilayah Kerja Puskesmas Glumpang Baro Kabupaten Pidie.

Pendapatan adalah hasil yang diperoleh dari kerja atau usaha yang telah dilakukan. Pendapatan akan mempengaruhi gaya hidup seseorang. Pendapatan adalah hasil pencarian atau perolehan dari usah. Menurut Sumardi dan Evers (2009), pendapatan yaitu keseluruhan penerimaan yang diterima baik berupa uang maupun barang dari pihak lain maupun dari hasil usaha sendiri. Jadi yang dimaksud pendapatan adalah suatu penghasilan yang diperoleh dari pekerjaan utama dan pekerjaan tambahan dari orang tua dan anggota keluarga lainya. Pendapatan keluarga yang memadai akan menunjang tumbuh kembang anak, karena orang tua dapat menyediakan semua kebutuhan yang perlukan anak baik yang primer maupun yang sekunder (Soetjiningsih, 2010).

Penelitian terdahulu yang dilakukan oleh Muhammad (2011) tentang hubungan pendidikan dengan kelengkapan status imunisasi pada balita di Wilayah Kerja Puskesmas Panteraja diperoleh hasil bahwa ada hubungan antara pendidikan dengan kelengkapan status imunisasi pada balita, $\mathrm{p}$ value $=0,000$. 
Berdasarkan hasil penelitian, peneliti berasumsi bahwa pendidikan turut memberikan konstribusi terhadap pengetahuan responden, semakin tinggi pengetahuan yang ditempuh, turut memberikan pengaruh terhadap pengetahuan yang dimiliki.

Asumsi peneliti di dukung oleh teori yang dikemukakan oleh Notoatmodjo (2012) yang menyatakan bahwa pendidikan dapat mempengaruhi seseorang termasuk juga prilaku seseorang akan kepatuhannya, terutama dalam motivasi untuk berperan serta dalam pembangunan kesehatan. Makin tinggi pendidikan seseorang, maka makin mudah menerima informasi sehingga makin banyak pula pengetahuan yang dimilikinya, sehingga dapat mengurangi ketegangan emosional. Sebaliknya pendidikan yang kurang akan menghambat perkembangan sikap seseorang terhadap perubahan-perubahan hidup sehat.

\section{KESIMPULAN}

Berdasarkan hasil penelitian dan pembahasan Hubungan sosial ekonomi ibu dengan kelengkapan Imunisasi Pada Anak di Wilayah Kerja Puskesmas glumpang Baro Kecamatan Glumpang Baro Kabupaten Pidie Tahun 2018, maka dapat disimpulkan bahwa :

1. Ada hubungan antara pendidikan dengan kelengkapan imunisasi di Wilayah Kerja Puskesmas Glumpang Baro Tanjong Kabupaten Pidie.

2. Ada hubungan antara pendapatan ibu dengan kelengkapan imunisasi di Wilayah Kerja Puskesmas Glumpang Baro Kabupaten Pidie.

\section{DAFTAR PUSTAKA}

Anonymos, 2009. Imunisasi Suatu Permulaan Yang Sehat. Unicef, Jakarta.

Atika Putri Dewi, Dkk. 2013. Tingkat pengetahuan Ibu Dengan Pemberian Imunisasi Dasar Lengkap Pada Bayi. Diunduh Tanggal 02 Oktober 2018

Depkes RI. 2014. kesehatan ibu dan anak. Jakarta

Dinas Kesehatan Pidie, 2010. Data Imunisasi.

Fida dan Maya. 2012. Pengantar ilmu Ksehatan Anak. Yogyakarta: D-Medika

Hidayat, A. 2009. Ilmu Kesehatan Anak. Jakarta: Selemba Medika

Hidayat, A. 2012. Pengantar Ilmu Keperawatan Anak: Jakarta Selemba Medika.

Hidayat, B. Pujiarto, P.S \& Gunardi, H. 2014. Hepatitis B. In IDAI, Pedoman Imunisasi di Indonesia. Jakarta: IDAI.

I. G.N Ranuh, Dkk,2014. Pedoman Imunisasidi Indonesia. Jakarta: Ikatan Dokter Anak Indonesia

Kemenkes RI, 2013. Pedoman Penyelenggaraan Imunisasi. Jakarta.

Kemenkes RI. 2016. Imunisasi Efektif Menekan Angka Kesakitan dan Kematian Anak . Retrieved From Depkes RI

Maryunani. 2010. Ilmu Kesehatan Anak Dalam Kebidanan. Jakarta: TIM

Muhammad, 2011. Hubungan pendidikan dengan kelengkapan status imunisasi pada balita di Wilayah Kerja Puskesmas Panteraja.

Notoadmojo, 2012. Promosi kesehatan dan prilaku kesehatan. Jakarta: Rineka cipta

Notoatmodjo, 2012. Ilmu Prilaku Kesehatan. Jakarta: Rhineka Cipta

Notoatmodjo, S. 2011. Kesehatan Masyaraka, Ilmu Dan Seni.Ed. Rev.-Jakarta: Rineka Cipta

Permenkes RI. 2013. Jadwal Pemberian Imunisasi. Jakarta .

Proverawati, A. Dkk. 2010. Imunisasi San Vaksinasi. Yogyakarta: Nuha Medika

Putra, Satiatava Rizema. 2012. Asuhan Neonatus, Bayi dan Balita Untuk Keperawatan dan Kebidanan. Yogyakarta: D-Medika.

Rochman. K. M. 2011. Faktor Yang Berhubungan Dengan Tindakan Ibu Dalam Pemberian Imunisasi Dasar Pada Bayi Di Kabupaten Koto Gowa. Di Peroleh Tanggal 04 September 2018. Dari http://repository

Satiatava, R.P. 2012. asuhan neonates bayi dan balita untuk keperawatan dan kebidanan. Jogjakarta : D-MEDIKA

Soetjiningsih, 2010. Tumbuh Kembang Remaja dan permasalahannya. Jakarta: EGC 